\title{
Pharma sets its sights on secondary data use
}

Electronic health records (EHRs) have providers and the public buzzing over their benefits, but pharmaceutical companies are excited, too-along with better safety surveillance and more efficient trial recruitment, this electronic information could trim the industry's expenses. If companies gain access, that is.

Currently, EHRs fall within the realm of health providers, with clinicians and insurers also reaping most of the benefits. But, at a higher level, electronic systems could be treasure troves for secondary data use, a term referring to the aggregation of EHRs for research and other purposes. If pharma, for example, can get its hands on the data-medication use, adverse event reports and more-it could be a huge boon to the industry, decreasing the cost of its own data collection efforts, starting with drug targeting and on through post-market surveillance. A recent report by Deloitte-_Modernizing the Pharmaceutical Development Process with EHRs"—estimated that EHRs could cut the costs in an average phase 3 trial by $\$ 5$ million.

However, access to reap those rewards is limited. In 2009, a PricewaterhouseCoopers survey found that $90 \%$ of pharmaceutical companies had zero or only partial access to EHR data from providers. It's largely a result of EHRs' youth; policies surrounding them are still in the early stages, and "it remains unclear how and with whom providers can share or even sell their data," says Frances Morrison, a researcher with Columbia University's Department of Biomedical Informatics in New York.

The US government has stepped in, at least partly, to look at data sharing. In December 2007, the National Committee on Vital and Health Statistics (NCVHS) made recommendations to the Department of Health and Human Services for what's being called 'data stewardship'. The NCVHS report, though, was a collection of guidelines, and actual implementationbringing data sets together and opening them up for use- remains largely up in the air.
All this has pharma anxious. Given the billions in stimulus funds put toward EHRs, health care providers will soon be riding a wave of data. Unless things change, the pharmaceutical industry could be left behind, sticking to the smaller data sets and trials it has coasted on for years. "If health care has the data, but pharma doesn't, we get an imbalance in the market," says Steven Labkoff, a former medical executive with Pfizer, who presented on this topic at a New York Academy of Sciences conference last month.

Concerns remain about privacy and the potential for companies to exploit data for marketing purposes. The NCVHS guidelines were a start, but Labkoff and Morrison agreed that future enforcement seems unlikely, and the public will need to understand the great value there is in accessing EHR data. "Put simply," Labkoff says, "medicine will not be advanced if there are limits to accessing aggregated data."

Christian Torres, New York

\section{Small practices find little incentive to go electronic}

Last year, the US government set aside $\$ 19$ billion in stimulus funds to lure providers into adopting electronic health records (EHRs). But while large hospitals and networks take the lead, small physician practices, which make up the majority of health care providers, could lag behind.

Under the 2009 Health Information Technology for Economic and Clinical Health (HITECH) Act, there are financial incentives for doctors who digitize, as well as penalties for those who don't. The effects, however, are relative; larger providers face larger incentives and penalties, whereas smaller providers might find that the cost of implementation cancels out the incentive.

The numbers might even go so far as to make it financially optimal-at least in the short term-to stick with paper records and pay the penalty: a 2009 study by the advisory firm Avalere Health found that upgrading to EHRs could cost $\$ 124,000$ for a single doctor or small practice, easily outweighing the $\$ 44,000$ in government incentives, as well as the $\$ 5,100$ yearly penalty for nonadopters.

And for years small practices have indeed lagged behind. In a survey of

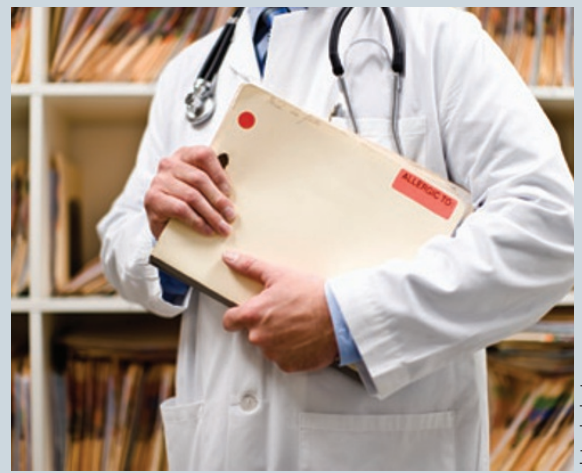

On file: Small clinics cling to paper trail

nearly 2,800 physicians, those in practices of five or fewer doctors accounted for nearly half of all physicians who hadn't yet adopted EHRs (N. Engl. J. Med. 359, 50-60; 2008). Similarly, a 2003-2004 survey by the US National Center for Health Statistics found that only $13 \%$ of physicians in a practice of four or fewer used electronic medical records. Those same physicians, however, accounted for nearly three-quarters of ambulatory care visits at that time.

Not just a modernization issue, the electronic records gap could prove a problem for research, too. The government's
Agency for Healthcare Research and Quality (AHRQ), for example, is putting $\$ 300$ million in stimulus funds toward comparative-effectiveness researchstudies comparing one treatment option to another-with projects including a national network that would cultivate data from EHRs.

Although the network would be able to incorporate smaller practices and their data, that may be a ways off. According to Jean Slutsky, director of AHRQ's Center for Outcomes and Evidence, future research "will take advantage of existing EHR networks," but whether small practices are ready to contribute their vast data in the near term "is up for question."

Reeling in small providers, then, might require extra help from Washington. Last June, Kathy Dahlkemper, a congressional representative from Pennsylvania, introduced a bill that would establish a government loan program for smallpractice physicians who want to implement electronic systems. As Nature Medicine went to press, the bill was still in the hands of a Senate committee.

Christian Torres, New York 